\title{
Fibrosing alveolitis and polymyositis
}

\author{
PETER L. THOMPSON and IAN R. MACKAY \\ Clinical Research Unit of the Walter and Eliza Hall Institute and the Royal Melbourne Hospital, \\ Victoria 3050, Australia
}

A case of fibrosing alveolitis and polymyositis is described. We think that this, in association with previously published reports, favours a real and not fortuitous association. The basis for the association may be an abnormality of immunity, but this could not be established in the present case nor from those previously published.

There have been five reported instances of polymyositis and diffuse fibrosing alveolitis in the one patient (Mills and Mathews, 1956 ; Goldfischer and Rubin, 1959 ; Hyun, Diggs, and Toone, 1962 ; Pace, Decker, and Martin, 1963 ; Sandbank, Grunebaum, and Katzenellenbogen, 1966). Additional but less definite cases were reported by Pace et al. (1963), in which the pulmonary changes were more suggestive of the arteritis of systemic sclerosis, and by Peralta and Carril (1962), in which there was no histological confirmation of alveolitis.

We suspect that some instances of coexisting polymyositis and fibrosing alveolitis are unrecog- nized because both conditions are treated with corticosteroid drugs (Scadding and Hinson, 1967 ; Rose and Walton, 1966), which could mask the manifestations of the coexisting condition or result in myositis being diagnosed as a 'steroid myopathy'. We present a patient with fibrosing alveolitis who was not treated with corticosteroids; florid polymyositis was noted at necropsy.

\section{CLINICAL DETAILS}

The patient was a 60-year-old Greek woman. In 1965 she had night sweats and transient pains in the hands, elbows, and knees, and in May 1968 a dry cough and

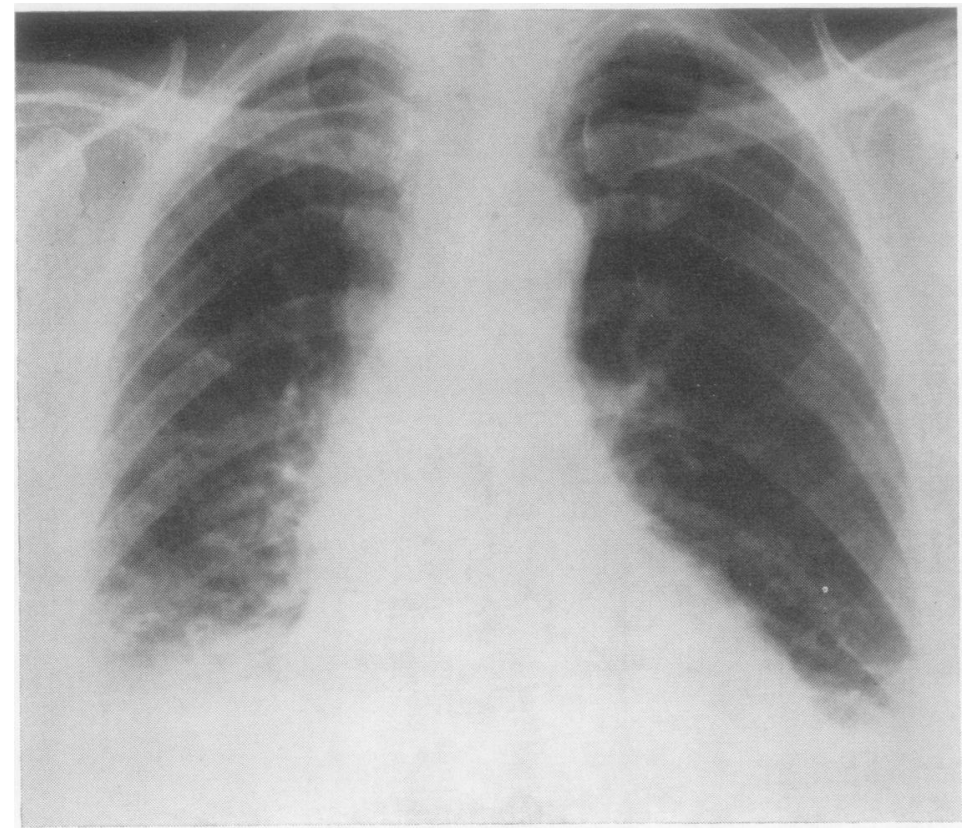

FIG. 1. Chest radiograph in September 1968, showing diffuse mottling of lung bases, worse on the right. 
interscapular pleuritic pains with physical signs of bilateral basal bronchopneumonia. Antibiotics were given without improvement. She was sent to hospital with the diagnosis of 'unresolved pneumonia'. She gave no history relevant to tuberculosis, inhalation of dusts or contact with birds.

Physical examination in hospital in June 1968 showed no fever, a respiratory rate of 20 /minute, and bronchial breathing at both lung bases with fine crepitations to the mid-scapular level. There was slight swelling of all metacarpophalangeal joints, slight scaling of the skin over the joints of the hands, and pitting of the nails. The chest radiograph showed mottling of both lung bases (Fig. 1). Examination of the sputum for cells and micro-organisms, bronchoscopy, and bronchography all gave normal results. Respiratory function tests showed progressive restriction, ventilation-perfusion imbalance with a small amount of true veno-arterial shunting and a gas transfer defect (Table). An open lung biopsy showed

T A B L E

RESPIRATORY FUNCTION TESTS

\begin{tabular}{|c|c|c|c|c|c|}
\hline & & $\begin{array}{l}\text { Normal } \\
\text { Values }\end{array}$ & $\underset{\text { ber }}{\text { Septem- }}$ & $\begin{array}{c}\text { Octo- } \\
\text { ber }\end{array}$ & $\begin{array}{c}\text { Novem- } \\
\text { ber }\end{array}$ \\
\hline $\begin{array}{l}\text { Tidal volume (ml.) } \\
\text { Vital capacity (1.) } \\
\text { Arterial } \mathrm{PO}_{2}(\mathrm{~mm} . \mathrm{Hg}) \\
\text { (breathing room air) } \\
\text { Arterial } \mathrm{PO}_{2}(\mathrm{~mm} . \mathrm{Hg}) \\
\left.\text { (breathing } 100 \% \mathrm{O}_{2}\right) \\
\text { Arterial } \mathrm{POO}_{2}\left(\mathrm{~mm} . \mathrm{Hg}^{2}\right) \\
\text { Alveolar-arterial } \mathrm{PO}_{2} \\
\text { difference }\left(\mathrm{mm} . \mathrm{Hg}^{2}\right) \\
\text { Fractional carbon } \\
\text { monoxide uptake }(\%)\end{array}$ & $\begin{array}{l}\cdots \\
\cdots \\
\cdots \\
\cdots \\
\cdots \\
\cdots\end{array}$ & $\begin{array}{c}400-600 \\
2 \cdot 5 \pm 0 \cdot 5 \\
80-100 \\
>550 \\
35-45 \\
<15 \\
40-45\end{array}$ & $\begin{array}{l}381 \\
1 \cdot 26 \\
63 \\
410 \\
35 \\
39 \\
31\end{array}$ & $\begin{array}{l}347 \\
0.91 \\
72 \\
527 \\
38 \\
23 \\
33\end{array}$ & $\begin{array}{l}150 \\
- \\
- \\
- \\
-\end{array}$ \\
\hline
\end{tabular}

changes of fibrosing alveolitis (vide infra). In November 1968 she developed dysphagia, dysphonia, and regurgitation of fluids into the nose and there were signs of partial bulbar palsy and muscle weakness. The edrophonium (Tensilon) test was negative. Her condition deteriorated rapidly, cough became ineffective, the tidal volume dropped to $150 \mathrm{ml}$., and the respiratory rate increased to 40 /minute. An electromyogram showed infrequent biphasic spikes indicative of myopathy. She died from respiratory failure.

\section{NECROPSY}

There were small pleural effusions and pleural adhesions. The lungs were fibrotic, the right weighing $375 \mathrm{~g}$. and the left $305 \mathrm{~g}$. Other findings were unremarkable.

histological eXamination The lung biopsy and necropsy sections (Fig. 2) showed disorganization of the alveolar structure with widespread fibrosis, thickening of the alveolar walls, and infiltration with lymphocytes and plasma cells but no arteritis ; special stains showed no food particles, fat, or inhaled matter.

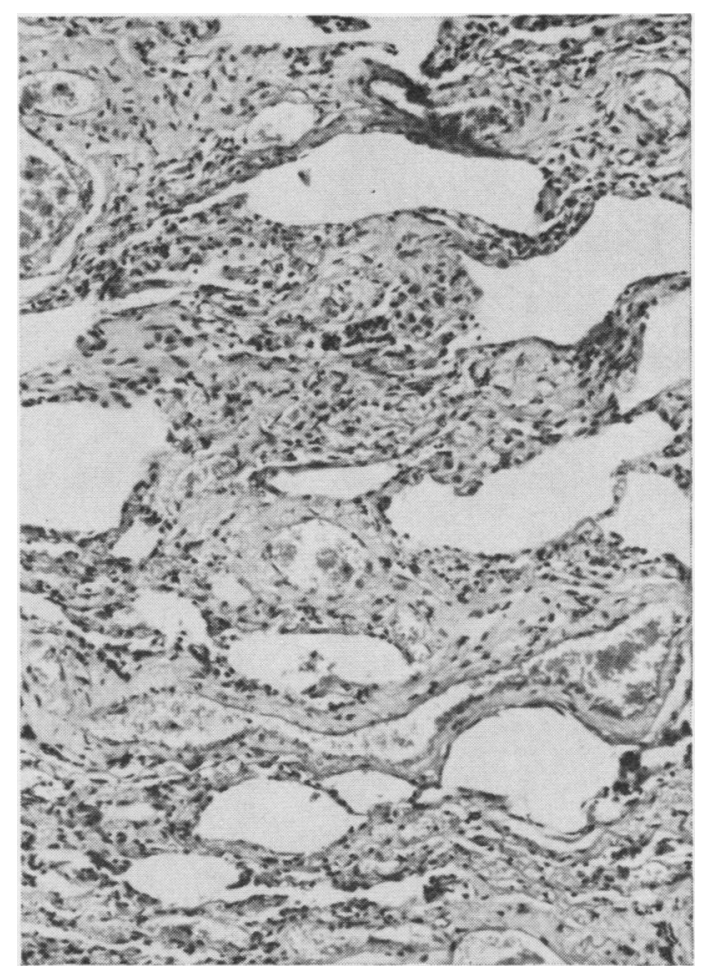

FIG. 2. Section of lung biopsy showing thickening of septa and infiltration with lymphocytes and plasma cells. $H$. and $E . \times 120$.

Necropsy section of the posterior pharyngeal muscles (Fig. 3) showed necrosis and regeneration of muscle fibres, phagocytosis of necrotic fibres, interstitial fibrosis, and infiltration with lymphocytes and plasma cells. Similar changes were seen in all muscles examined; Fig. 4 shows a focus of necrosis with lymphocyte aggregation in the right deltoid muscle.

AUTOIMMUNE SEROLOGICAL INVESTIGATIONS Serological tests for autoantibodies were performed as described by Whittingham and Mackay (1969). Tests for LE cells, antinuclear factor, rheumatoid factor, and cold agglutinins were negative. A portion of the lung biopsy was snap frozen and cryostat sections were examined by immunofluorescence for deposited immunoglobulin: none was detected.

\section{DISCUSSION}

The coexistence of fibrosing alveolitis has been described with several suspected autoimmune diseases including rheumatoid arthritis (Scadding, 1969), chronic hepatitis (Turner-Warwick, 1968), 


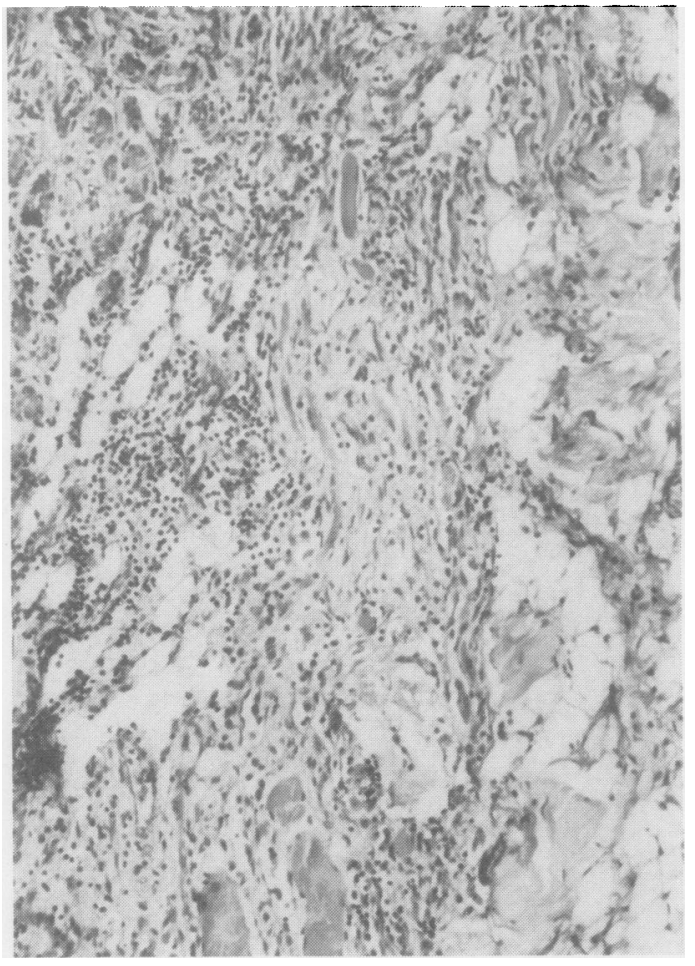

FIG. 3. Section of posterior pharyngeal muscle taken at necropsy showing degeneration and necrosis of muscle fibres, fatty replacement, and infiltration with lymphocytes and plasma cells. $H$. and $E . \times 120$.

Sjögren's disease (Tomasi, Fudenberg, and Finby, 1962), and autoimmune haemolytic anaemia (Mackay and Ritchie, 1965). Moreover, autoimmune serological reactions have been demonstrated in fibrosing alveolitis. Rheumatoid factors were demonstrated in $61 \%$ of 18 patients by Tomasi et al. (1962). Turner-Warwick and Doniach (1965) studied 48 cases and found rheumatoid factors in $49 \%$ and antinuclear factors in $28 \%$.

An attractive hypothesis, similar to that proposed by Dixon (1968) for some cases of human glomerulonephritis, is that circulating immune complexes precipitate in pulmonary capillaries, causing inflammation and fibrosis. This has been demonstrated in the rabbit lung (McKinnon, Andrews, Heptinstall, and Germuth, 1957). However, we could not demonstrate immunoglobulins in the lungs of our patient, nor could they be demonstrated by Turner-Warwick and Doniach (1965) nor by Mackay and Ritchie (1965).
Although polymyositis is also associated with rheumatoid arthritis and other possible autoimmune diseases (Rose and Walton, 1966), its status as an autoimmune disease is even less certain.

Search for circulating autoantibodies in polymyositis has been unrewarding (Caspary, Gubbay, and Stern, 1964). Two experimental studies suggest that a disturbance of cellular immunity may be concerned. Dawkins (1965) produced a histological lesion similar to human polymyositis by injection of heterologous skeletal muscle into guinea-pigs ; when these animals were subsequently tested, they showed delayed-type skin responses to skeletal muscle. Kakulas (1966) demonstrated destruction of rat skeletal muscle in tissue culture by sensitized lymphocytes. The relevance of these experimental studies has not been established, as there are no reports of abnormalities of cellular immunity in human polymyositis.

Explanations for occasional associations of two diseases were discussed by Scadding (1969) in rela-

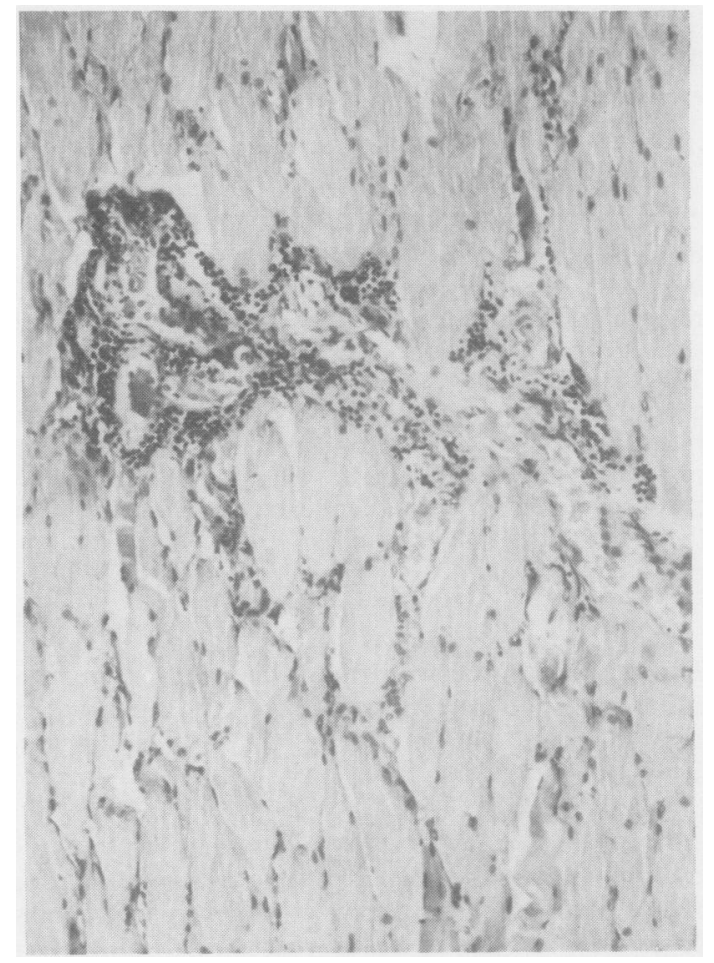

FIG. 4. Section of right deltoid taken at necropsy showing necrosis of muscle fibres and focal lymphocytic accumulation. $H$. and $E . \times 120$. 
tion to rheumatoid arthritis and fibrosing alveolitis; a single pathogenetic process common to both diseases was only one of several possible explanations considered and, although it seemed the most likely, such a common process has yet to be formally demonstrated. A similar conclusion is applicable to the present association of polymyositis with fibrosing alveolitis. The evidence cited above suggests the presence in both conditions of processes which could be broadly regarded as 'autoimmune', but the pathways in the two diseases differ. In fibrosing alveolitis the available evidence points to an abnormality of humoral immune mechanisms, whereas the experimental findings pertaining to polymyositis, if indeed applicable to the human disease, are more suggestive of an abnormality of cellular immune mechanisms.

We wish to thank Drs. Michael Pain and John Cade for performing and interpreting the respiratory function tests, and Dr. Ben Wadham and the late Mr. Roy Ingles for help in preparation of the photomicrographs.

\section{REFERENCES}

Caspary, E. A., Gubbay, S. S., and Stern, G. M. (1964). Circulating antibodies in polymyositis and other muscle-wasting disorders. Lancet, 2, 941 .

Dawkins, R. L. (1965). Experimental myositis associated with hypersensitivity to muscle. J. Path. Bact., 90, 619.
Dixon, F. J. (1968). The pathogenesis of glomerulonephritis. Amer. J. Med., 44, 493.

Goldfischer, J., and Rubin, E. H. (1959). Dermatomyositis with pulmonary lesions. Ann. intern. Med., 50, 194

Hyun, B. H., Diggs, C. L., and Toone, E. C. (1962). Dermatomyositis with cystic fibrosis (honeycombing) of lungs. Dis. Chest, 42, 449.

Kakulas, B. A. (1966). In vitro destruction of skeletal muscle by sensitized cells. Nature, Lond., 210, 1115.

Mackay, I. R., and Ritchie, B. (1965). Diffuse fibrosing alveolitis (diffuse interstitial fibrosis of the lungs): two cases with autoimmune features. Thorax, 20, 200.

McKinnon, G. E., Andrews, E. C., Jr., Heptinstall, R. H., and Germuth, F. G., Jr. (1957). An immunohistologic study on the occurrence of intravascular antigen-antibody precipitation and its role in anaphylaxis in the rabbit. Bull. Johns Hopk. Hosp. $101,258$.

Mills, E. S., and Mathews, W. H. (1956). Interstitial pneumonitis in dermatomyositis. J. Amer. med. Ass., 160, 1467.

Pace, W. R., Decker, J. L., and Martin, C. J. (1963). Polymyositis: report of two cases with pulmonary function studies suggestive
of progressive systemic sclerosis. Amer. J. med. Sci., 245, 322.

Peralta, M. G., and Carril, R. F. F. (1962). Fibrosis pulmonar diffusa y dermatomiositis. Rev. clin. esp., 84, 114.

Rose, A. L., and Walton, J. N. (1966). Polymyositis: a survey of 89 cases with particular reference to treatment and prognosis. Brain, 89, 747.

Sandbank, M., Grunebaum, M., and Katzenellenbogen, I. (1966). Dermatomyositis associated with subacute pulmonary fibrosis. Arch. Derm., 94, 432.

Scadding, J. G. (1969). The lungs in rheumatoid arthritis. Proc. roy. Soc. Med., 62, 227.

- and Hinson, K. F. W. (1967). Diffuse fibrosing alveolitis (diffuse interstitial fibrosis of the lungs). Correlation of histology at biopsy with prognosis. Thorax, $22,291$.

Tomasi, T. B., Fudenberg, H. H., and Finby, N. (1962). Possible relationship of rheumatoid factors and pulmonary disease. Amer. J. Med., 33, 243.

Turner-Warwick, M. (1968). Fibrosing alveolitis and chronic liver disease. Quart. J. Med., 37, 133.

— and Doniach, D. (1965). Auto-antibody studies in interstitial pulmonary fibrosis. Brit. med. J., $1,886$.

Whittingham, S., and Mackay, I. R. (1969). Laboratory methods for diagnosis of autoimmune disease. Med. J. Aust., 1, 1200. 